\title{
Capacitación y comportamiento financiero de la generación millennial en España
}

\author{
Marcos Álvarez Espiñoa / Sara Fernández-López / Lucía Rey-Ares ${ }^{\mathrm{b}}$ / Sandra Castro-González*c \\ a Universidade de Santiago de Compostela - Facultade de Ciencias Económicas e Empresariais \\ b Universidade da Coruña - Facultade de Humanidades e Documentación de Ferrol \\ c Universidade de Santiago de Compostela - Facultade de Administración e Dirección de Empresas de \\ Lugo
}

Recibido: 27 de julio de 2020 / Aceptado: 19 de noviembre de 2020

\begin{abstract}
Resumen
La capacitación o competencia financiera de los individuos, resultado de la combinación de su cultura financiera y de la oportunidad de acceder a los productos financieros, supone un reto en las sociedades actuales y, particularmente, para ciertos colectivos de población como la generación millennial. Por esta razón, es importante conocer la competencia financiera de los millennials y constatar si existen diferencias con respecto a las generaciones predecesoras. Tras la revisión de la literatura, el análisis empírico se basa en una muestra de datos extraída de la Encuesta de Competencias Financieras (ECF). La muestra está conformada por unas 6.852 personas no jubiladas menores de 65 años, de las cuales aproximadamente un 34\% son millennials, y sobre ellas se aplicarán sendos análisis estadístico-descriptivos y econométricos. La evidencia empírica sugiere que la capacidad financiera de los individuos está más condicionada por su cultura financiera que por sus oportunidades de acceso a productos financieros. Sin embargo, la inclusión financiera se relaciona en mayor medida con los comportamientos financieros de los encuestados. Esta relación es clara, con independencia de la cohorte generacional analizada, en el retraso en pagos, en el mantenimiento de fondos de emergencia y en el horizonte de planificación financiera. También se detecta que la relación que mantienen algunos comportamientos con la capacitación financiera es más similar entre los millennials adultos y los no millennials, que cuando se compara a los primeros con sus congéneres. Esta investigación contribuye a la literatura financiera existente a través del análisis de la competencia financiera de la generación millennial en España y de cómo esta influye en su comportamiento financiero. En este sentido, el trabajo aporta evidencias empíricas a un campo de estudio en el que apenas existen investigaciones que vayan más allá de los análisis centrados en contextos anglosajones.
\end{abstract}

Palabras clave

Cultura financiera / Inclusión financiera / Competencia financiera / Millennials / España.

\section{Financial capability and financial behaviour of the millennial generation in Spain}

\begin{abstract}
Individuals' financial capability, resulting from the combination of the financial literacy they have and the opportunity to access financial products, is a challenge in today's societies and, particularly, for certain population groups such as the millennial generation. For this reason, it is important to study the financial capability of millennials and to validate whether there are differences regarding that of preceding generations. After the literature review, the empirical analysis is carried out using a sample based on the Survey of Financial Competences (SFC). The sample is composed of 6,852 non-retired individuals under 65 years of age, of which approximately $34 \%$ are millennials. Descriptive and econometric analyses are based on this sample. However, financial inclusion is more related to the financial behaviours of respondents. This relationship is clear, regardless of the generational cohort analysed, in the delay in payments, the maintenance of emergency funds and the financial planning horizon. It is also found that the correlation of some behaviours with financial literacy is more similar between millennials and non-millennials than when the former is compared with their peers. This research contributes to the existing financial literature through the analysis of the financial capability of the Spanish millennial generation and the analysis of how this capability influences its financial behaviour. In this sense, the research brings empirical evidence to a field of study in which there is hardly any reference that goes beyond descriptive analyses focused on AngloSaxon contexts.
\end{abstract}

Keywords

Financial literacy / Financial inclusion / Financial capability / Millennials / Spain.

JEL Codes: G31, G32, G40.

* Correspondencia autora: sandra.castro@usc.es 


\section{Introducción}

En un entorno en el que la complejidad de las finanzas en general (Rodríguez-Castellanos, 2019), y de los productos financieros en particular, no ha dejado de crecer en las últimas décadas (Klapper, Lusardi y van Oudheusden, 2015), disponer de una buena cultura financiera es cada vez más necesario. No obstante, según la última encuesta de S\&P Global FinLit Survey, elaborada por el Global Financial Literacy Excellence Center (2020), en España solamente el 49\% de su población adulta tiene una cultura financiera aceptable. Asimismo, nuestros jóvenes de 15 años obtienen una menor puntuación en competencia financiera que la media de los países OCDE, según el informe PISA en sus ediciones tanto de 2012 como de 2015 (Organisation for Economic Co-operation and Development [OECD], 2013, 2016). Ahora bien, como señala Sherraden (2013), el hecho de tener una buena cultura financiera, por sí mismo, no garantiza un comportamiento financiero óptimo por parte de los individuos, sino que este depende también de las oportunidades que los individuos tengan a su alcance. Así, es la combinación de ambos aspectos -esto es, conocimiento y oportunidad- lo que se denomina capacitación o competencia financiera (Friedline y West, 2016; Sherraden, 2013).

En el contexto actual, condicionado por las secuelas que traerá la incertidumbre económica desencadenada por la pandemia COVID-19, la falta de competencia financiera resulta más preocupante entre los millennials. Esta generación, conformada por aquellos nacidos entre los años 1980 y 2000, se ha incorporado al mercado laboral en un contexto económico marcado por la Gran Recesión y sus consecuencias, entre las que se encuentran una disminución de oportunidades y una mayor precariedad laboral (Cutler, 2015; Kim, Anderson y Seay, 2019; McLendon, 2016). En este sentido, este cúmulo de dificultosas circunstancias propicia un panorama complejo que aboca a la generación millennial a tomar decisiones en un contexto de enorme incertidumbre (Cramer, 2014). Aunque abundan los trabajos que tienen como objeto de estudio el nivel de competencia financiera en sí misma, en particular referidos a los jóvenes estudiantes de 15 años a raíz de la información contenida en los informes PISA, apenas existen estudios que exploren cómo dicha competencia se relaciona con los comportamientos financieros de las personas. La escasez de trabajos que estudien este tema no reside tanto en el desinterés por analizar este grupo de individuos como en la falta de datos sólidos para contrastar las hipótesis, dado que las bases de datos que permiten obtener una muestra representativa de la generación millennial no han estado disponibles hasta hace relativamente poco tiempo.

En este sentido, los objetivos de la presente investigación se resumen en tres: (1) conocer la competencia financiera de los millennials españoles, distinguiendo entre millennials jóvenes (nacidos entre los años 1990 y 1998) y millennials adultos (nacidos entre 1980 y 1989), pues, aunque pertenecen a la misma generación, pueden encontrarse en etapas de su vida muy diferentes que condicionan totalmente su ciclo de vida financiero; (2) explorar cómo esa competencia se relaciona con sus actitudes y comportamientos financieros; y (3) comprobar si dicha relación difiere en el caso de las generaciones predecesoras. Para ello, esta investigación analiza una muestra de 6.852 personas no jubiladas menores de 65 años que ha sido extraída de la Encuesta de Competencias Financieras (ECF).

Tras esta introducción, el segundo epígrafe continúa con la revisión de la literatura más reciente, y el tercer y cuarto epígrafes se reservan para la presentación de la metodología y de los resultados empíricos, respectivamente. Finalmente, el quinto epígrafe remata con la síntesis de las principales conclusiones del trabajo.

\section{Revisión de la literatura: millennials y competencia financiera}

Los millennials son individuos que vivieron su infancia y adolescencia en un entorno de expansión económica truncado por la Gran Recesión iniciada en el año 2008 (Cutler, 2015). A partir de entonces, el contexto económico en el que se incorporaron al mercado laboral ha provocado que esta generación tenga una menor renta disponible que las generaciones precedentes a su misma edad (Campos, 2019). Asimismo, sus expectativas vitales y su forma de entender la vida provocan que esta generación aho- 
rre menos que las generaciones anteriores (Fernández-López, Vivel-Búa, Rey-Ares y Sixto-Puente, 2020). Los millennials ahorran poco con vistas a su jubilación (Mottola, 2014; Yao y Cheng, 2017), pues consideran que aún les queda mucho tiempo antes de abandonar el mercado laboral (Foster, Ng y Wee, 2015). Igualmente, la desconfianza que les inspiran las instituciones financieras por su papel en la crisis económica iniciada en el año 2008 (Lövgren y Magnusson, 2016) tampoco favorece su ahorro.

Además, aunque la generación millennial suele tener menos productos financieros que las generaciones predecesoras, asume mayores costes en su uso. Es el caso de la posesión de tarjetas de crédito. Aunque los millennials poseen un porcentaje inferior, tienden a exceder los límites de disponibilidad, a retrasar pagos o a sacar dinero por adelantado (Mottola, 2014). Igualmente, están altamente endeudados en términos de préstamos a largo plazo. Por su corta edad, mantienen menos préstamos hipotecarios que las generaciones previas (de Bassa, Lusardi y Yakoboski, 2014), pero más préstamos estudiantiles (Cornejo-Saavedra, Umaña-Hermosilla, Guíñez Cabrera, Muñoz-Silva y Mardones-Lagos, 2017). Como resultado de lo anterior, esta generación se ve abocada a un menor ahorro del que puedan realizar otras (Cramer, 2014).

Esto también puede responder a una serie de actitudes que definen a esta generación del milenio, que tiende a exhibir comportamientos financieros más preocupantes que los que, a su misma edad, mostraban las generaciones precedentes (Kim et al., 2019; Mottola, 2014). A modo de ejemplo, aunque están preocupados por la complejidad de la situación financiera a la que se enfrentan, son reticentes a buscar asesoramiento financiero profesional (de Bassa et al., 2014).

En este contexto económico y financiero tan complejo, la formación de los jóvenes en cuestiones financieras ha sido una de las intervenciones básicas que desde las Administraciones se han llevado a cabo para ayudarles a evitar comportamientos financieros peligrosos (Lusardi y Mitchel, 2014). Klapper et al. (2015) definen la cultura financiera como la habilidad para entender los conceptos financieros esenciales que permitan tomar decisiones adecuadas en lo relativo a ahorro, a la inversión o a la financiación. Por tanto, tal y como apuntan Hastings, Madrian y Skimmyhorn (2013), la cultura financiera exige cierto tipo de conocimientos (por ejemplo, conceptos o productos financieros), combinados con determinadas habilidades (como el cálculo numérico) y actitudes (por ejemplo, la capacidad de planificación a largo plazo). En esta misma línea se articula la definición de alfabetización financiera utilizada en los informes PISA (Ministerio de Educación, Cultura y Deporte [MECD], 2014).

No obstante, la educación financiera por sí sola puede resultar insuficiente para impulsar comportamientos financieros positivos en los individuos, especialmente en los millennials que, hasta la reciente crisis provocada por la pandemia COVID-19, y desde la Gran Recesión, se han enfrentado a unas condiciones macroeconómicas desfavorables (Friedline y West, 2016) en que se han visto obligados a tomar decisiones financieras que marcarán buena parte de su vida. En particular, Cole, Paulson y Shastry (2016) demuestran que cursar educación financiera no influye significativamente en comportamientos como la acumulación de activos o la gestión del crédito. Por ello, recientemente algunos investigadores han sugerido la necesidad de combinar los conocimientos financieros con la inclusión financiera, con el fin de mejorar la toma de decisiones de los individuos (Friedline y West, 2016; Sherraden, 2013) o la propia alfabetización financiera (Moreno-Herrero, Salas-Velasco y Sánchez-Campillo, 2018a, 2018b). La inclusión financiera condiciona la oportunidad de las personas de acceder a aquellos productos o servicios financieros acordes con sus necesidades. Según Anderloni, Bayot, Bledowski, Iwanicz-Drozdowska y Kempson (2008), esa oportunidad es un aspecto determinante en la vida social y económica del individuo, que influye de forma notoria en su inclusión o exclusión social.

La combinación de ambos factores -cultura financiera e inclusión financiera- da lugar a la competencia o capacitación financiera de los individuos (Friedline y West, 2016; Sherraden, 2013), que los llevará a tomar mejores decisiones en la medida en que posean los conocimientos necesarios para ello (cultura financiera) y la oportunidad de aplicarlos (inclusión financiera) (Friedline y West, 2016; Sherraden, 2013).

En la literatura existente no son pocos los trabajos que evidencian una menor cultura financiera de los jóvenes (Lusardi y Mitchell, 2007; Shim, Barber, Card, Xiao y Serido, 2010). En el caso particular de la generación millennial, este resultado se repite. Los millennials suelen presentar menores conoci- 
mientos financieros que las generaciones anteriores (Cornejo-Saavedra et al., 2017; Kim et al., 2019; Mottola, 2014) y, en cambio, tienden a autoevaluar dichos conocimientos de forma más elevada (de Bassa et al., 2014; Kim et al., 2019).

También abundan los estudios que analizan la competencia financiera de los adolescentes a raíz de su evaluación a través de los informes PISA a partir del año 2012. En general, estos trabajos se centran en los factores que pueden incidir en esa competencia financiera; es decir, la competencia financiera es la variable dependiente. Así, Moreno-Herrero et al. (2018b) encuentran que los estudiantes de los países cuyos sistemas educativos presentan una mayor calidad en la formación matemática y científica tienen un mayor nivel de alfabetización financiera. Del mismo modo, cuando los padres hablan con ellos sobre temas relacionados con el dinero, su alfabetización financiera mejora (Moreno-Herrero et al., 2018b). Igualmente, el uso o la exposición a productos financieros, como una cuenta bancaria o una tarjeta de débito de prepago, aumenta el conocimiento financiero de los estudiantes (Moreno-Herrero et al., 2018a, 2018b). También el desarrollo de las habilidades matemáticas o el nivel educativo de la familia, en particular el de la madre, ejercen un papel mediador en la evolución de las competencias financieras de los jóvenes españoles (Mancebón, Ximénez-de-Embún, Mediavilla y Gómez-Sancho, 2019). Por su parte, Cordero y Pedraja (2019) recomiendan la inclusión de la educación financiera no como asignatura en sí misma, sino transversalmente, incorporándola en otras materias, para, de este modo, mejorar la adquisición de conocimientos financieros por parte de los adolescentes. Por el contrario, Molina, Marcenaro y Martín (2015) detectan que aquellos sistemas educativos que han articulado una materia separada para la impartición de la educación financiera obtienen un impacto relevante sobre el grado de desarrollo de esta competencia entre sus adolescentes.

En contraste con la literatura mencionada, apenas existen trabajos que exploren los comportamientos financieros de los millennial y su relación con la competencia financiera o, de forma separada, con la cultura e inclusión financieras. De hecho, hasta donde sabemos, el trabajo de Friedline y West (2016) es el único que ha abordado el tema. En concreto, las autoras analizan cómo la competencia financiera de los millennials se relaciona con diferentes aspectos financieros, tales como la fragilidad financiera; la retención de ahorros de emergencia; el uso de instrumentos financieros alternativos, como los payday loans ${ }^{1}$; la posesión de deuda; o la satisfacción financiera general. Los resultados constatan que los millennials "financieramente competentes", comparados con el resto de las categorías (a saber: "financieramente incluidos", "financieramente formados" y "financieramente excluidos"), tienen mayores probabilidades de poseer fondos de emergencia y experimentan una mayor satisfacción en relación con aspectos financieros. Al mismo tiempo, tienen menores probabilidades de recurrir a "deudas malas", de percibir que tienen demasiada carga financiera o de experimentar fragilidad financiera. Además, mientras la inclusión financiera desempeña un papel significativo en todos los comportamientos, no ocurre así con la cultura financiera, puesto que las diferencias entre los financieramente formados y los financieramente excluidos no son significativas a la hora de explicar el uso de fuentes alternativas de financiación o la percepción de una importante carga financiera.

Por otra parte, Kim et al. (2019) también realizan un estudio centrado en los comportamientos financieros de los millennials, pero considerando únicamente la influencia de la cultura financiera y no la de la inclusión financiera. En general, los autores concluyen que la cultura financiera objetiva está positivamente relacionada con buenos hábitos financieros tanto en el corto como en el largo plazo, mientras que la cultura financiera subjetiva se muestra únicamente relacionada con estos últimos.

En definitiva, como se ha mencionado anteriormente, en este trabajo se pretende: (1) analizar la competencia financiera, tal y como la definen Friedline y West (2016), de los millennials españoles, en concreto de los millenials jóvenes y de los millennials adultos; (2) explorar cómo esa competencia financiera se relaciona con sus actitudes y comportamientos financieros; y (3) comprobar si esa relación difiere en el caso de las generaciones predecesoras. Hasta donde sabemos, ningún estudio ha abordado el análisis de estas posibles relaciones para la población española.

\footnotetext{
${ }^{1}$ Los payday loans, o préstamos de día de pago, son préstamos por cantidades reducidas, a muy corto plazo y con muy altas tasas de interés (https://www.investopedia.com/terms/p/payday-loans.asp).
} 


\section{Metodología}

\subsection{Muestra}

El análisis empírico de este trabajo se basa en la Encuesta de Competencias Financieras (ECF) que, elaborada de manera conjunta por el Banco de España y por la Comisión Nacional del Mercado de Valores (CNMV), tiene como propósito analizar los conocimientos financieros de la población española con edades comprendidas entre los 18 y los 80 años. Los datos de esta encuesta están referidos a los años 2016 y 2017, período en el que se realizó el trabajo de campo a través de encuestas personales.

A partir de la muestra original, integrada por 8.554 personas entrevistadas, la muestra de estudio se restringió a aquellas personas entre 18 y 64 años que no estuviesen jubiladas en el momento de la entrevista. Ello dio como resultado una muestra final de 6.852 individuos ${ }^{2}$. Para su clasificación en grupos de edad se utilizó como referencia su año de nacimiento, considerando como millennials a quienes hubiesen nacido en 1980 o en años posteriores, mientras que al resto se les calificó como "no millennials". Es más, dentro de los primeros se distinguieron dos grupos: millennials jóvenes (nacidos entre 1990 y 1998) y millennials adultos (nacidos entre 1980 y 1989), dado que el momento del ciclo de vida en el que se encuentran puede provocar más diferencias dentro de esta generación que con respecto a otras, esto es, al comparar a los millennials adultos (en la treintena en el momento de realizar la encuesta) con personas de la generación no millennial. La muestra quedó integrada por un $15,29 \%$ de millennials jóvenes, un $18,39 \%$ de millennials adultos y un $66,32 \%$ de no millennials.

Para todos los cálculos que se presentan a continuación se usaron los pesos muestrales proporcionados por la ECF que, una vez consideradas las "no respuestas", habían sido ajustados para reflejar la estructura demográfica -básicamente, sexo, edad y nacionalidad por comunidad autónoma- de la población española según el Censo de 2011 (Banco de España, 2019; Bover, Hospido y Villanueva, 2019).

\subsection{Variables}

\subsubsection{Variables dependientes}

Este estudio considera como variables dependientes diferentes variables proxy del comportamiento financiero de los individuos. En particular, se han buscado en la ECF variables similares a las estudiadas por Friedline y West (2016) y Kim et al. (2019), con el objetivo de que los resultados puedan ser, en la medida de lo posible, comparables. Así, se han utilizado las variables recogidas en la Tabla 1, algunas de las cuales ya eran originalmente de naturaleza dicotómica mientras que otras fueron transformadas a partir de variables en formato tipo escala Likert.

Tabla 1. Definición de las variables dependientes

\begin{tabular}{|c|c|c|c|}
\hline Variable & Definición & $\begin{array}{l}\text { Friedline y West } \\
\qquad(2016)\end{array}$ & $\begin{array}{l}\text { Kim et al. } \\
\text { (2019) }\end{array}$ \\
\hline Presupuestación ${ }^{1}$ & $\begin{array}{l}\text { ¿Hace en su hogar una planificación de los gastos? Es } \\
\text { decir, decide periódicamente, por ejemplo, qué parte de } \\
\text { la renta del hogar se usa para gastar, ahorrar o pagar } \\
\text { recibos. }\end{array}$ & & $\begin{array}{l}\text { Budgeting } \\
\quad(0,1)\end{array}$ \\
\hline $\begin{array}{l}\text { Horizonte de } \\
\text { planificación }{ }^{2}\end{array}$ & $\begin{array}{l}\text { Me he fijado objetivos financieros a largo plazo y me es- } \\
\text { fuerzo por alcanzarlos. }\end{array}$ & & $\begin{array}{l}\text { Financial goals } \\
\qquad(0,1)\end{array}$ \\
\hline
\end{tabular}

2 No obstante, el tamaño de las muestras puede variar para cada variable dependiente estudiada en función del número de individuos que respondieron a cada pregunta. 
Tabla 1 (continuación). Definición de las variables dependientes

\begin{tabular}{|c|c|c|c|}
\hline Variable & Definición & $\begin{array}{l}\text { Friedline y West } \\
\qquad(2016)\end{array}$ & $\begin{array}{l}\text { Kim et al. } \\
\text { (2019) }\end{array}$ \\
\hline Gasto $^{1}$ & $\begin{array}{l}\text { En los últimos } 12 \text { meses, ¿han sido sus gastos corrien- } \\
\text { tes mayores que sus ingresos? }\end{array}$ & & $\begin{array}{l}\text { Spending } \\
\quad(0,1)\end{array}$ \\
\hline $\begin{array}{l}\text { Fondos de } \\
\text { emergencia }{ }^{3}\end{array}$ & $\begin{array}{l}\text { Si dejase de recibir en este momento la principal fuente } \\
\text { de ingresos de su hogar ¿durante cuánto tiempo podría } \\
\text { hacer frente a sus gastos corrientes sin tener que pedir } \\
\text { prestado o cambiar de casa? }\end{array}$ & $\begin{array}{l}\text { Emergency } \\
\text { saving } \\
(0,1)\end{array}$ & $\begin{array}{l}\text { Emergency } \\
\text { funds }(0,1)\end{array}$ \\
\hline $\begin{array}{l}\text { Retraso en } \\
\text { pagos }^{1}\end{array}$ & $\begin{array}{l}\text { En los últimos } 12 \text { meses, ¿han tenido en su hogar difi- } \\
\text { cultades económicas que hayan dado lugar a retrasos } \\
\text { en el pago de alguna de las deudas contraídas? }\end{array}$ & & \\
\hline $\begin{array}{l}\text { Carga } \\
\text { financiera }^{2}\end{array}$ & Estoy demasiado endeudado ahora mismo. & $\begin{array}{l}\text { Debt burden } \\
\quad(0,1)\end{array}$ & \\
\hline $\begin{array}{l}\text { Satisfacción } \\
\text { financiera }^{2}\end{array}$ & Estoy satisfecho con mi situación financiera actual. & $\begin{array}{l}\text { Financial } \\
\text { satisfaction } \\
(0-10)\end{array}$ & \\
\hline
\end{tabular}

Notas: ${ }^{1}$ Variable dicotómica: (1) Sí; (0) No. ${ }^{2} 1$ si en una escala de 1 (totalmente en desacuerdo) a 5 (totalmente de acuerdo), la persona está de acuerdo (4) o totalmente de acuerdo (5), 0 para el caso de que la escala tome valores inferiores. ${ }^{3}$ Variable dicotómica: (1) para las respuestas que indican "Por lo menos 3 meses" o más; (0) para las respuestas que indican menos de 3 meses. Fuente: elaboración propia.

\subsubsection{Variables independientes}

La variable de interés es la competencia o capacitación financiera que, siguiendo a Friedline y West (2016), se crea a partir de la combinación de diferentes variables que miden, por un lado, la cultura financiera y, por otro, la inclusión financiera. Así, en lo que se refiere a la cultura financiera se han tenido en cuenta tres cuestiones, de forma análoga a Lusardi y Mitchell (2011), relativas a los tipos de interés, la inflación y la diversificación de riesgos (véase la Tabla 2). A partir de las tres cuestiones anteriores se ha construido una variable categórica que mide el número de respuestas correctas (cultura financiera: 0 ninguna, 1 baja, 2 media y 3 alta).

Por su parte, la inclusión financiera puede considerarse, hasta cierto punto, un proceso gradual. Por ello, se procedió a buscar en la ECF qué cuestiones podrían reflejar mejor dicho proceso y que resultasen similares a las medidas de inclusión expuestas por Friedline y West (2016). En concreto, se encontraron las cuestiones recogidas en la Tabla 2, que permitieron crear también una variable categórica que mide el número de productos financieros que la persona posee de forma individual o conjunta (inclusión financiera: 0 baja, 1 media y 2 alta $^{3}$ ).

A partir de las variables anteriormente descritas, y siguiendo el patrón establecido por Friedline y West (2016), se han creado dos variables distintas de competencia financiera en función del producto financiero adquirido (cuentas de ahorro y tarjetas de crédito) que, a su vez, tienen dos variantes en función del nivel de cultura financiera del individuo (ver la Tabla 3). De este modo, se han combinado las variables de inclusión y cultura financiera para construir un índice que oscila entre 0 y 3 , donde el valor 0 hace referencia a aquellos individuos que ni poseen un nivel alto de cultura financiera ni el

\footnotetext{
${ }^{3}$ En la presente versión del trabajo se muestran las estimaciones con la variable inclusión financiera tal y como fue descrita. No obstante, también se realizaron estimaciones considerando una variable de inclusión financiera que incorporaba la posesión de cuentas corrientes, libretas de ahorro u otros depósitos. Dado que se comprobó que prácticamente la totalidad de la muestra contaba con este tipo de productos, es decir, que esta variable no actuaba como filtro de la inclusión financiera de los individuos, se descartó incluirla en el subsiguiente análisis multivariante.
} 
producto financiero elegido (cuenta de ahorro/tarjeta de crédito). Son individuos, en terminología de Friedline y West (2016), "financieramente excluidos". Se asignaría un valor 1 a aquellos individuos "financieramente formados" (que han acertado las tres preguntas sobre conocimientos financieros); un valor 2 a aquellos individuos que disponen del producto financiero en cuestión, pero han fallado al menos una de las preguntas de cultura financiera -"financieramente incluidos"-; y un valor 3 para los que presentan tanto el producto financiero como conocimientos financieros altos -individuos "financieramente capacitados"-. La segunda variante considera financieramente formados a los individuos que han contestado correctamente dos de las tres cuestiones expuestas; es decir, suaviza el filtro referido a la cultura financiera.

Tabla 2. Definición de las variables independientes: cultura financiera e inclusión financiera

\begin{tabular}{|c|c|}
\hline Variables & Definición \\
\hline $\begin{array}{l}\text { Cultura financiera } \\
\text { objetiva } \\
\text { (Categorías: } 0-3 \text { ) }\end{array}$ & $\begin{array}{l}\text { Variable continua con un rango entre } 0 \text { y } 3 \text { en función del número de respuestas correc- } \\
\text { tas a las siguientes preguntas: } \\
\text { a. Suponga que deposita } 100 € \text { en una cuenta de ahorro con un interés fijo del } 2 \% \\
\text { anual. En esa cuenta no hay comisiones ni impuestos. Si usted no hace ningún } \\
\text { movimiento adicional, una vez que el interés le haya sido abonado, ¿de cuánto dinero } \\
\text { dispondrá en su cuenta después de } 5 \text { años? [Más de } 110 € \text { /Exactamente } 110 € / \text { Menos } \\
\text { de } 110 € / \text { Es imposible calcularlo con los datos facilitados/Otras respuestas]. } \\
\text { b. Es habitualmente posible reducir el riesgo de invertir en el mercado de títulos al } \\
\text { comprar una amplia variedad de títulos [Verdadero/Falso]. } \\
\text { c. Imagine que } 5 \text { hermanos tienen que esperar un año para obtener un importe de } 1000 \\
€, \text { y la inflación durante ese año es del } 1 \% \text {. Dentro de un año serán capaces de } \\
\text { comprar... [Más de lo que podrían comprar hoy con la misma cantidad de dinero/La } \\
\text { misma cantidad/Menos de lo que pueden comprar hoy/...]. }\end{array}$ \\
\hline $\begin{array}{l}\text { Cuentas de ahorro } \\
(0,1)\end{array}$ & $\begin{array}{l}\text { (1) Si posee, individual o conjuntamente, cuentas de ahorro o algún tipo de cuenta que } \\
\text { no pueda ser utilizada para hacer pagos con tarjetas o cheques; (0) en caso contrario. }\end{array}$ \\
\hline $\begin{array}{l}\text { Tarjeta de crédito } \\
(0,1)\end{array}$ & $\begin{array}{l}\text { (1) Si posee, individual o conjuntamente, cuentas corrientes o tarjetas de crédito; (0) } \\
\text { en caso contrario. }\end{array}$ \\
\hline $\begin{array}{l}\text { Inclusión financiera } \\
\text { (Categorías: } 0 \text { a } 2 \text { ) }\end{array}$ & $\begin{array}{l}\text { Si posee, individual o conjuntamente: (2) cuentas de ahorro... y tarjetas de crédito; (1) } \\
\text { algunos de los dos productos anteriores; ( } 0 \text { ) ninguno de los dos productos anteriores. }\end{array}$ \\
\hline
\end{tabular}

Fuente: elaboración propia.

Tabla 3. Definición de las variables de competencia financiera

\begin{tabular}{|c|c|c|c|c|}
\hline $\begin{array}{l}\text { Cuentas } \\
\text { de ahorro }\end{array}$ & Incl & $\begin{array}{l}\text { 0: No tiene el producto } \\
\text { financiero. }\end{array}$ & 0: Financieramente excluido. & 1: Financieramente formado. \\
\hline $\begin{array}{l}\text { Tarjetas } \\
\text { de crédito }\end{array}$ & & $\begin{array}{l}\text { 1: Sí tiene el producto } \\
\text { financiero. }\end{array}$ & 2: Financieramente incluido. & $\begin{array}{l}\text { 3: Financieramente capaci- } \\
\text { tado. }\end{array}$ \\
\hline
\end{tabular}

\begin{tabular}{|c|c|}
\hline \multicolumn{2}{|c|}{ Cultura financiera } \\
\hline \multicolumn{2}{|c|}{ Variante 1} \\
\hline $\begin{array}{l}0 \text { : Menos de tres respuestas } \\
\text { correctas. }\end{array}$ & 1: Tres respuestas correctas. \\
\hline \multicolumn{2}{|c|}{ Variante 2} \\
\hline $\begin{array}{l}\text { 0: Menos de dos respuestas } \\
\text { correctas. }\end{array}$ & \\
\hline 0: Financieramente excluido. & 1: Financieramente formado. \\
\hline 2: Financieramente incluido. & $\begin{array}{l}\text { 3: Financieramente capaci- } \\
\text { tado. }\end{array}$ \\
\hline
\end{tabular}

Fuente: elaboración propia. 


\subsubsection{Variables de control}

En la Tabla 4 se incluyen las variables de control utilizadas en el análisis. Para ello, se han seleccionado aquellas características sociodemográficas y económicas que la literatura tradicionalmente ha asociado con los comportamientos financieros estudiados.

Tabla 4. Definición de las variables de control

\begin{tabular}{|c|c|}
\hline Variable & Definición \\
\hline Edad & Variable continua que mide los años de las personas encuestadas. \\
\hline Sexo & Variable dicotómica: (1) si la persona encuestada es mujer; (0) en caso contrario. \\
\hline $\begin{array}{l}\text { Estado civil: } \\
\text { casado/a }\end{array}$ & $\begin{array}{l}\text { Variable dicotómica: (1) si la persona encuestada convive habitualmente con su pareja/cón- } \\
\text { yuge; (0) en caso contrario. }\end{array}$ \\
\hline $\begin{array}{l}\text { Hijos/as } \\
\text { dependientes }\end{array}$ & $\begin{array}{l}\text { Variable dicotómica: (1) si la persona encuestada convive en su domicilio con sus hijos/as } \\
\text { menores de } 18 \text { años, o con los de su pareja/cónyuge; }(0) \text { en caso contrario. }\end{array}$ \\
\hline Educación & $\begin{array}{l}\text { Variable continua que registra el nivel educativo más alto de los encuestados: (1) sin educa- } \\
\text { ción formal; }(2) \text { educación primaria completa; }(3) \text { alguna educación secundaria; (4) educa- } \\
\text { ción secundaria completa; (5) educación superior a la secundaria (educación vocacional o } \\
\text { universitaria). }\end{array}$ \\
\hline $\begin{array}{l}\text { Situación } \\
\text { laboral }\end{array}$ & $\begin{array}{l}\text { Variable dicotómica: (1) si la persona encuestada tiene empleo (por cuenta propia o ajena); } \\
\text { (0) en caso contrario. }\end{array}$ \\
\hline Ingresos & $\begin{array}{l}\text { Variable categórica que mide el total de ingresos brutos anuales del domicilio: }(1)<14.500 € \text {; } \\
\text { (2) 14.500-45.000€; y (3) >45.000€. }\end{array}$ \\
\hline $\begin{array}{l}\text { Aversión } \\
\text { al riesgo }\end{array}$ & $\begin{array}{l}\text { Variable dicotómica: (1) si la persona encuestada, en una escala del } 1 \text { al } 5 \text { manifiesta estar de } \\
\text { acuerdo (4) o totalmente de acuerdo (5) en no estar preparados para arriesgar su dinero al } \\
\text { ahorrar o al invertir en productos financieros: }(0) \text { en otro caso. }\end{array}$ \\
\hline
\end{tabular}

Fuente: elaboración propia.

\section{Resultados}

\subsection{Análisis univariante}

La Figura 1 muestra los pesos porcentuales de la población que presenta las actitudes y comportamientos financieros objeto de estudio, distinguiendo tres submuestras: millennials jóvenes, millennials adultos y no millennials.

Así, los millennials tienen, en general, un mayor cuidado a la hora de administrar sus recursos, pues aproximadamente un $70 \%$ reconoce decidir periódicamente qué parte de la renta del hogar destina a ahorrar y a gastar, frente a un $64 \%$ de las generaciones precedentes. De un modo similar se comporta la variable relativa a la formulación de objetivos a largo plazo, siendo este comportamiento mucho más habitual en los millennials, especialmente en el subgrupo de los más jóvenes. La diferencia con respecto a los no millennials supera los 15 puntos porcentuales.

Aproximadamente un 30\% de las tres submuestras declara que en el último año sus gastos corrientes han superado sus ingresos. No obstante, el efecto sobre la percepción del nivel de carga financiera asumida es diferente, al afirmar un mayor porcentaje de los no millennials tener un alto nivel de en- 
deudamiento. También estos afirman disponer de fondos de emergencia en mayor medida que los millennials.

En general, la satisfacción financiera es bastante alta (nótese que más de un $40 \%$ de todos los colectivos contestan en las dos categorías de respuesta más alta de la escala).

Al centrarse específicamente en los millennials, se aprecia que los comportamientos de los adultos se parecen más a los comportamientos de los no millennials que a los de sus congéneres más jóvenes. Dicho de otro modo, el porcentaje de personas que dentro de la submuestra millennial adultos presenta el comportamiento analizado está más próximo al porcentaje correspondiente en la submuestra no millenials que en la de millennials jóvenes. Las únicas excepciones se darían en el exceso de gasto durante el último año y en la satisfacción financiera, donde una menor proporción de millennials adultos manifestarían sentirse financieramente satisfechos en relación al nivel de satisfacción que refieren tanto los millennials jóvenes como los no millennials (en este caso el porcentaje coincide).

En general, los datos arrojan un comportamiento financiero de los encuestados bastante solvente, con una tenencia de ahorros de emergencia y una baja prevalencia de retrasos en el pago de deudas. No obstante, la "generación del milenio" tiende a planificar y administrar más sus recursos, posiblemente como resultado de la mayor escasez relativa y muestran una menor disponibilidad de fondos de emergencia. Las tendencias apuntadas se agravan si comparamos a los no millennials con los millennials jóvenes.

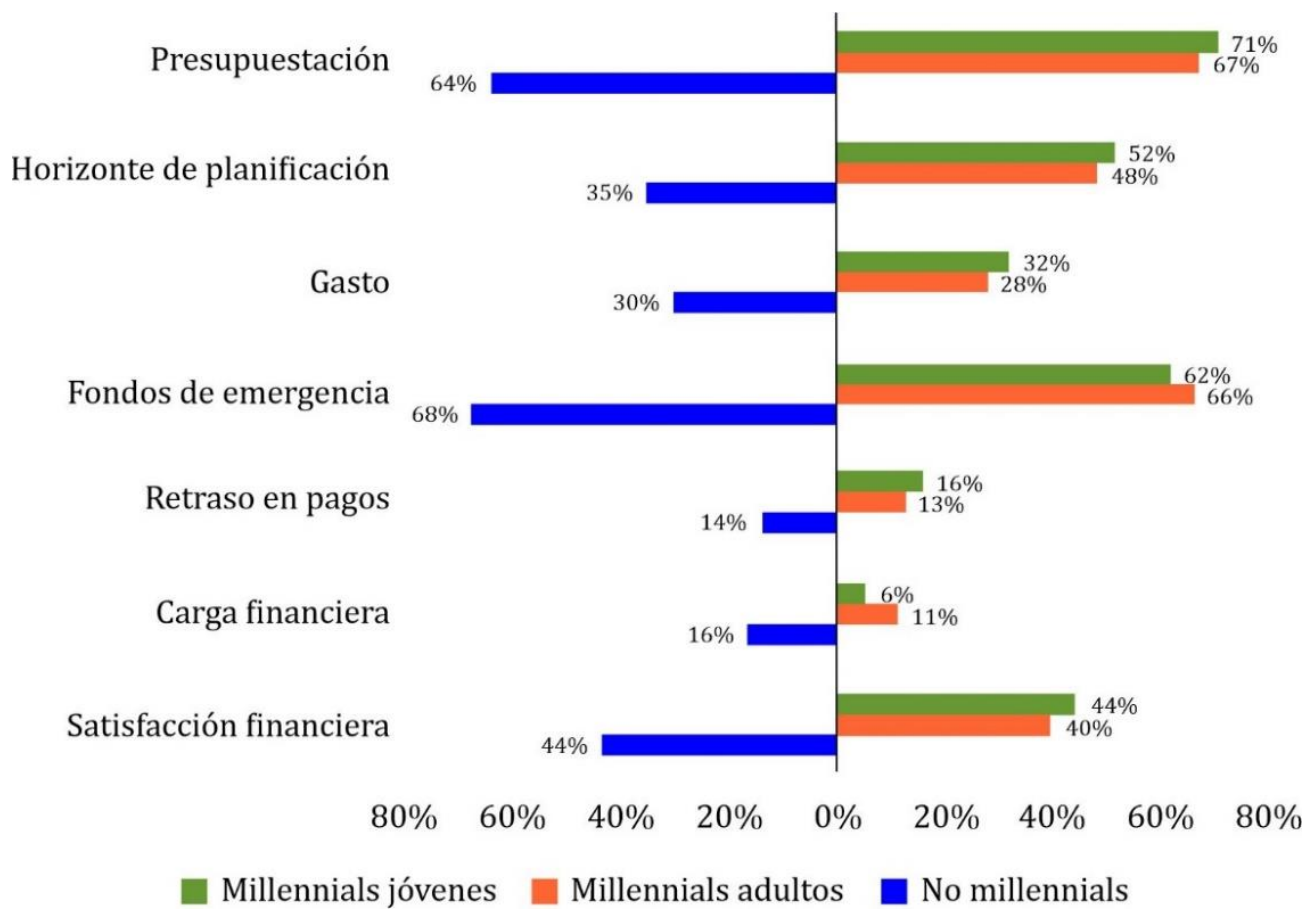

Figura 1. Individuos que presentan los comportamientos financieros analizados por grupo de población (\%). Notas: los pesos muestrales han sido utilizados. Fuente: elaboración propia.

En la Figura 2 se muestra el porcentaje de individuos en función del número de respuestas correctas a las tres preguntas de cultura financiera. Los datos indican un relativamente mayor nivel de cultura financiera entre las generaciones precedentes a la millennial. Así, el porcentaje de individuos que no contestan bien a ninguna de las tres preguntas es más alto dentro del colectivo millennial (un 16\% de los millennials adultos y un 18\% de los millennials jóvenes), mientras que la proporción de no millennials respecto de la de millennials de ambos grupos que contestan correctamente a las tres cuestiones es sensiblemente mayor $(21,39 \%)$. Estos indicadores de cultura financiera de la población española 
muestran una situación más optimista que la que se deduce de otras encuestas. Así, en su cuarta edición referida a 2011, la encuesta SHARE ${ }^{4}$ mostraba que de los 3.570 participantes españoles, solo 258 habían respondido a una cuestión relativa al cálculo del nominal y a los intereses de una cuenta corriente, y de estos, solo el 19\% lo había hecho correctamente (Pumares-Iglesias, Fernández-López, Vivel-Búa y Rey-Ares, 2015). En definitiva, la cultura financiera objetiva del colectivo millennial tiende a ser más baja, especialmente si nos centramos en los millennials más jóvenes. Este resultado coincide parcialmente con los apuntados por Cornejo-Saavedra et al. (2017), para el caso chileno, y por Kim et al. (2019) y Mottola (2014), para el caso estadounidense.

La Figura 3 presenta el porcentaje de individuos que, dentro de cada submuestra, cuenta con alguno de los productos financieros recogidos en la Tabla 3, tratando así de reflejar su nivel de inclusión financiera. Se puede concluir que casi la mitad de los millennials jóvenes no tienen acceso a ninguno de los dos productos financieros analizados (cuenta de ahorro y tarjeta de crédito). En cambio, un porcentaje bastante similar tanto de millennials adultos como de no millennials, levemente inferior al 50\%, afirma disponer de uno de los dos productos financieros. Al contrario, la proporción de no millennials con ambos productos (29\%) es más alta que la de millennials adultos, y casi el doble que la de millennials jóvenes. En definitiva, la exclusión financiera, tal y como se ha definido, es un problema más habitual en los millennials, sobre todo en los de menor edad.

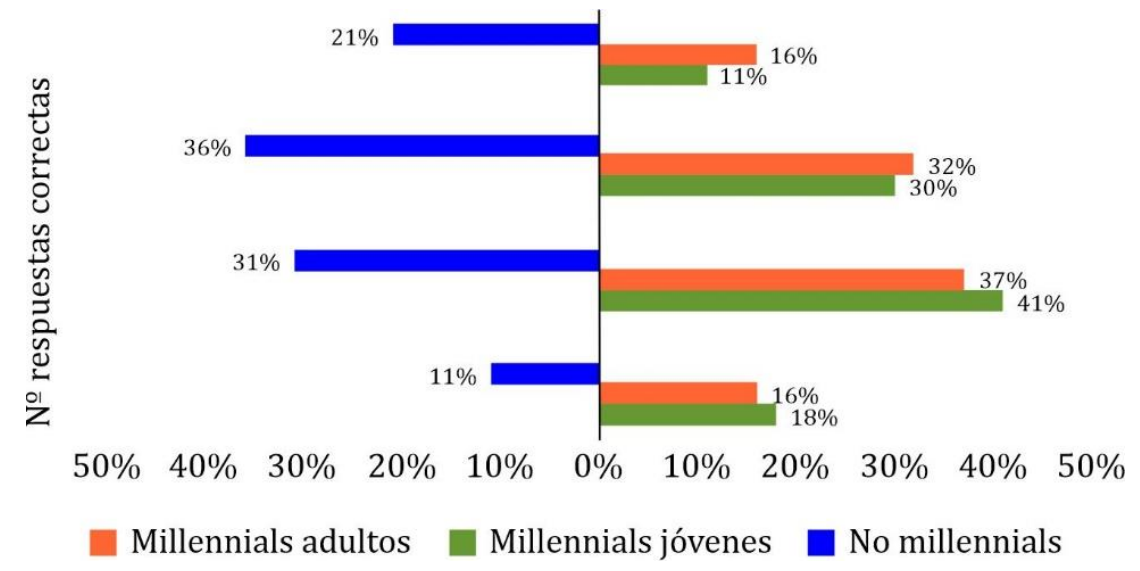

Figura 2. Individuos en función del número de respuestas correctas en cultura financiera por grupo de población (\%). Notas: los pesos muestrales han sido utilizados. Fuente: elaboración propia.

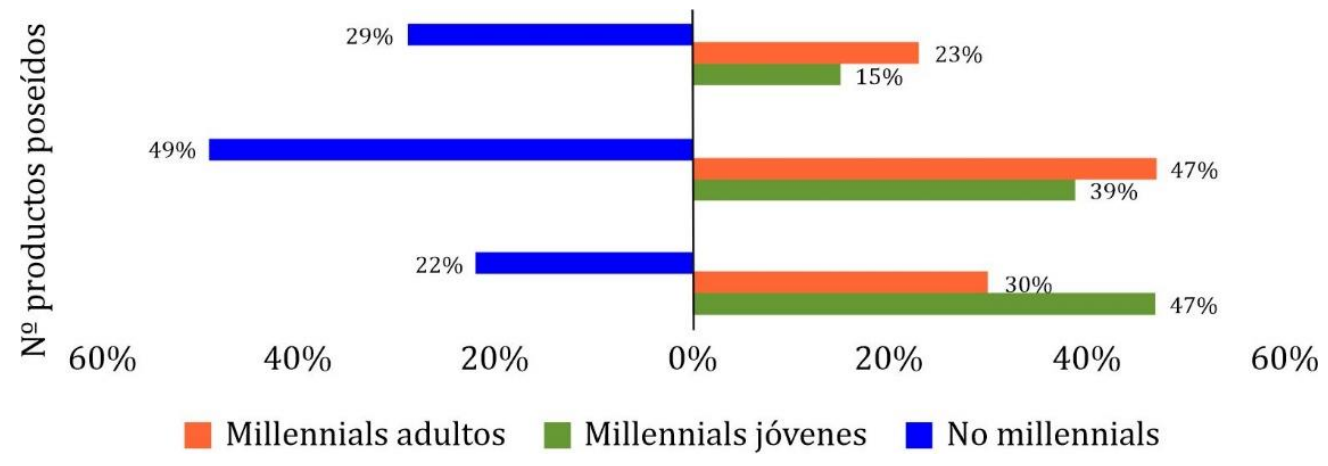

Figura 3. Individuos en función del número de productos que poseen (inclusión financiera) por grupo de población (\%). Notas: los pesos muestrales han sido utilizados. Fuente: elaboración propia.

${ }^{4}$ Survey of Health, Ageing and Retirement in Europe (SHARE). 
De manera similar, se procede a analizar la competencia financiera de los individuos encuestados (Figura 4). Es necesario recordar que las variables de capacitación o competencia financiera se distinguen por el producto financiero asociado y por el número de respuestas correctas para la variable cultura financiera. La variante "cultura financiera alta" exige que el individuo responda las tres preguntas correctamente para poder ser clasificado como financieramente formado o capacitado. La variante "cultura financiera media" es menos restrictiva y solo exige dos respuestas correctas.

Cultura financiera alta
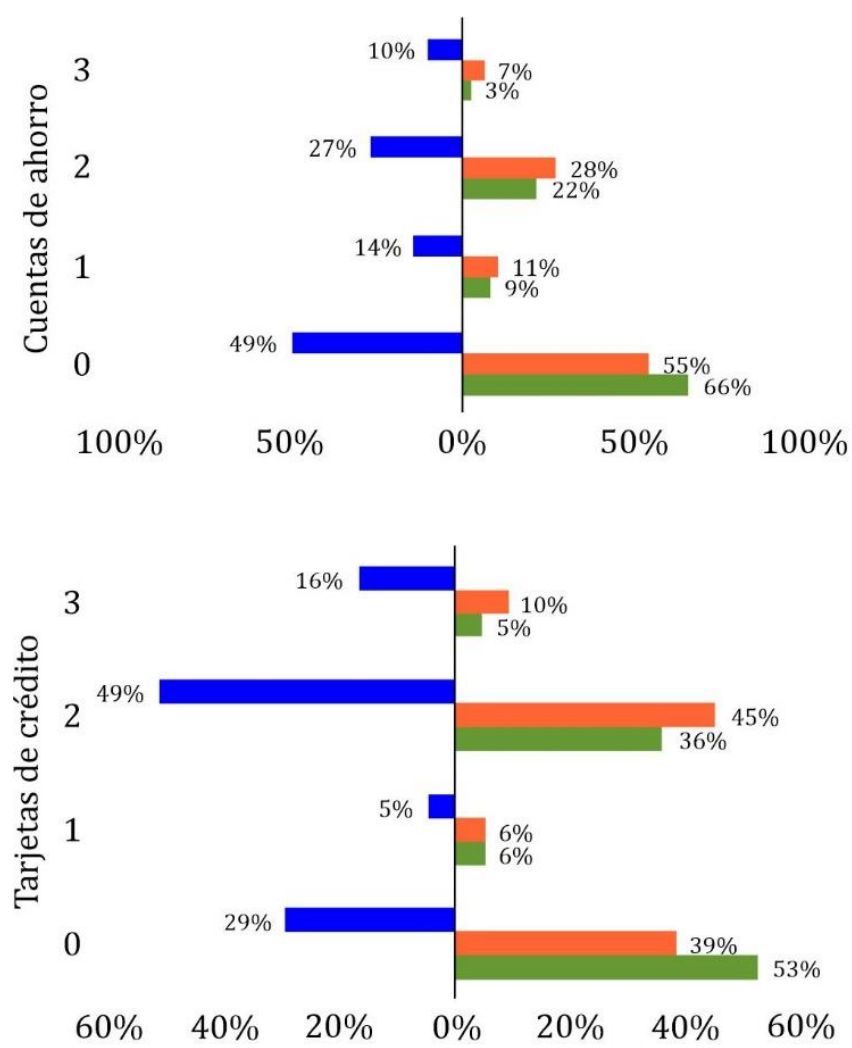

Cultura financiera media

3

2

1

0

$60 \%$

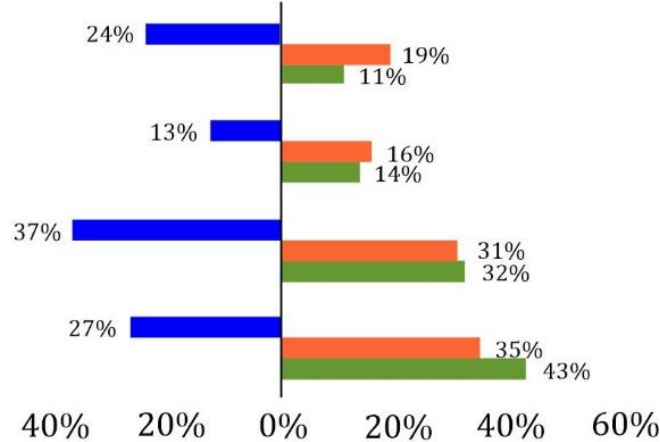

3

$41 \%$

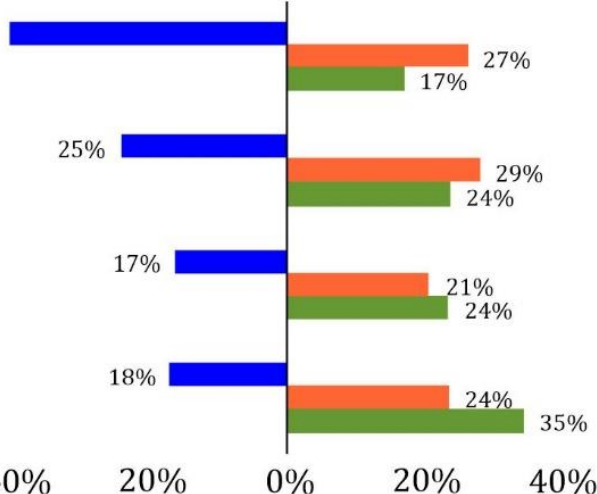

Millennials adultos Millennials jóvenes

No millennials

Figura 4. Individuos en función de su competencia financiera por grupo de población (\%). Notas: los pesos muestrales han sido utilizados. 0: Financieramente excluido; 1: Financieramente formado; 2: Financieramente incluido; 3: Financieramente capacitado. Fuente: elaboración propia.

Con carácter general, la menor exigencia de aciertos en la versión "cultura financiera media" provoca que los porcentajes de individuos excluidos disminuyan, al exigirse un menor número de respuestas correctas, a cambio de notables incrementos en los porcentajes de individuos financieramente incluidos.

La comparación entre los productos financieros nos lleva a concluir que la tarjeta de crédito es un producto más habitual en la población que las cuentas de ahorro. Nótese que la proporción de individuos financieramente incluidos o capacitados es notablemente superior en los figuras inferiores respecto de las figuras superiores.

En todo caso, la tendencia general es que los millennials, y especialmente los más jóvenes, tienen un menor acceso a los productos analizados y un menor nivel de cultura financiera respecto de los no millennials. Los millennials adultos, como viene siendo habitual, suelen estar en un punto intermedio, 
con un nivel de competencia financiera superior al de los millennials de menor edad, pero inferior al de los no millennials.

Por tanto, y en relación con el primero de los objetivos formulados en este trabajo, podemos concluir que la competencia financiera de las personas encuestadas, tal y como ha sido definida, no es muy elevada, con independencia de la submuestra analizada. Únicamente la mayor presencia de la tarjeta de crédito provoca que más de la mitad de los millennials adultos y de los no millennials se agrupen en los valores superiores de la variable. No obstante, en los demás casos, y sobre todo para los millennials jóvenes, esos porcentajes son sensiblemente inferiores. Se puede concluir, también, que la cultura financiera condiciona la capacitación financiera de los individuos en mayor medida que la exclusión financiera. Esto puede ser debido a que en el trabajo se han seleccionado unos productos financieros relativamente extendidos entre la población española.

Finalmente, la Tabla 5 muestra el porcentaje de población que presenta la característica analizada dentro de cada submuestra. Aproximadamente la mitad de las personas encuestadas son mujeres, con independencia de la submuestra.

Tabla 5. Distribución de la población por submuestras

\begin{tabular}{|c|c|c|c|c|}
\hline & & $\begin{array}{l}\text { Millennials } \\
\text { jóvenes }\end{array}$ & $\begin{array}{l}\text { Millennials } \\
\text { adultos }\end{array}$ & $\begin{array}{c}\text { No } \\
\text { millennials }\end{array}$ \\
\hline \multicolumn{2}{|c|}{ Sexo: mujer } & $48,76 \%$ & $51,01 \%$ & $50,99 \%$ \\
\hline \multicolumn{2}{|l|}{ Edad* } & 22 & 32 & 49 \\
\hline \multicolumn{2}{|c|}{ Situación laboral: empleado } & $34,32 \%$ & $74,93 \%$ & $70,09 \%$ \\
\hline \multirow[t]{3}{*}{ Ingresos } & $<14.500$ & $37,95 \%$ & $36,81 \%$ & $33,81 \%$ \\
\hline & $14.500-45.000$ & $50,79 \%$ & $51,91 \%$ & $49,11 \%$ \\
\hline & $>45.000$ & $11,26 \%$ & $11,28 \%$ & $17,08 \%$ \\
\hline \multirow[t]{5}{*}{ Educación } & Sin educación formal & $0,22 \%$ & $1 \%$ & $1,91 \%$ \\
\hline & Completa educación primaria & $6,89 \%$ & $7,87 \%$ & $13,21 \%$ \\
\hline & Alguna educación secundaria & $23,97 \%$ & $27,52 \%$ & $33,76 \%$ \\
\hline & Completa educación secundaria & $50,83 \%$ & $28,50 \%$ & $25,12 \%$ \\
\hline & Educación superior a la secundaria & $18,09 \%$ & $35,11 \%$ & $26 \%$ \\
\hline \multicolumn{2}{|c|}{ Hijos/as dependientes: sí } & $5,94 \%$ & $40,91 \%$ & $45,13 \%$ \\
\hline \multicolumn{2}{|c|}{ Estado civil: en pareja/cónyuge } & $11,51 \%$ & $59,64 \%$ & $76,87 \%$ \\
\hline \multicolumn{2}{|c|}{ Aversión al riesgo: averso } & $17,57 \%$ & $28,87 \%$ & $66,58 \%$ \\
\hline
\end{tabular}

Notas: los pesos muestrales han sido utilizados. *Muestran el valor medio de las variables continuas. Fuente: elaboración propia.

Alrededor de un 70\% de los millennials adultos y de los no millennials estarían en una situación de empleo, siendo la proporción algo más alta en los primeros. El nivel de empleo cae de manera radical (unos 40 puntos porcentuales) en el caso de los millennials jóvenes. Esta diferencia podría explicarse por encontrarse todavía en período de formación (el porcentaje de millennials jóvenes con estudios superiores, el más bajo de las tres muestras, resulta demasiado bajo, si tenemos en cuenta el elevado número de miembros del colectivo con educación secundaria superada). En esta línea de razonamiento, el porcentaje de millennials adultos con educación superior es notablemente mayor al de no millennials. 
El nivel de ingresos brutos anuales del hogar parece tener una relación positiva con la mayor edad del encuestado. A pesar de ello, la amplia mayoría de los encuestados, de cualquier colectivo, declaran tener unos ingresos brutos circunscritos al tramo medio de los tres propuestos.

Los millennials presentan un menor nivel de aversión al riesgo que las generaciones precedentes, especialmente los millennials de menor edad. Por ello, mientras más de la mitad de los no millennials $(66,58 \%)$ declara no estar preparada para arriesgar su dinero, al ahorrar o al invertir en productos financieros, este porcentaje disminuye hasta aproximadamente una cuarta parte entre los millennials de las dos submuestras expuestas.

\subsection{Análisis multivariante}

En este apartado se presentan los resultados de las estimaciones realizadas para alcanzar el segundo y el tercer objetivo de este estudio. De un modo más específico, los modelos expuestos buscan determinar si existe alguna asociación entre las variables referidas a la competencia financiera y las actitudes y comportamientos financieros de los millennials (jóvenes y adultos), y si esa relación varía en el caso de los no millennials. Las variables dependientes hacen referencia a siete comportamientos y actitudes financieras, y tienen naturaleza dicotómica. Por ello, es necesario realizar una estimación alternativa al Mínimo Cuadrado Ordinario (MCO), optando, en este caso, por regresiones probit binomiales.

En concreto, tras formular un modelo básico que incluía las variables de control, se incorporaron en un primer modelo las variables categóricas cultura financiera e inclusión financiera a fin de comprobar si ambas variables (por separado) guardaban alguna relación con los comportamientos estudiados. A partir de ese primer modelo se definieron otros cuatro, sustituyendo las variables cultura financiera e inclusión financiera por cada una de las cuatro proxies de competencia financiera (donde cultura e inclusión financiera se combinan). Estos cinco modelos se estimaron para cada variable dependiente (un total de siete) y para las tres submuestras (millennials jóvenes, millennials adultos y no millennials), resultando un total de 105 modelos estimados. Por su parte, la Tabla 6 resume los resultados obtenidos de los modelos estimados con respecto a las variables independientes objeto de estudio ${ }^{5}$.

Tabla 6. Resumen de los resultados para las variables de competencia financiera por grupo de población y comportamiento financiero

\begin{tabular}{|c|c|c|c|c|c|c|c|}
\hline & & & & \multicolumn{4}{|c|}{ VARIABLES DE COMPETENCIA FINANCIERA } \\
\hline & & \multicolumn{2}{|c|}{ Modelo 1} & Modelo 2 & Modelo 3 & Modelo 4 & Modelo 5 \\
\hline $\begin{array}{l}\text { Comportam./ } \\
\text { /Actitud }\end{array}$ & Submuestra & $\begin{array}{l}\text { Cultura } \\
\text { fin. }\end{array}$ & $\begin{array}{l}\text { Inclusión } \\
\text { fin. }\end{array}$ & $\begin{array}{c}\text { Compet. fin. } \\
\text { (cuentas ahorro } \\
+ \\
\text { cultura fin. } \\
\text { alta) }\end{array}$ & $\begin{array}{c}\text { Compet. fin. } \\
\text { (cuentas ahorro } \\
+ \\
\text { cultura fin. } \\
\text { media) }\end{array}$ & $\begin{array}{c}\text { Compet. fin. } \\
\text { (tarjeta créd. } \\
+ \\
\text { cultura fin. } \\
\text { alta) }\end{array}$ & $\begin{array}{c}\text { Compet. fin. } \\
\text { (tarjeta créd. } \\
+ \\
\text { cultura fin. } \\
\text { media) }\end{array}$ \\
\hline Presupuestación & $\begin{array}{l}\text { MJ } \\
\text { MA } \\
\text { NM }\end{array}$ & & & Capacitado (-) & & & Capacitado (-) \\
\hline \multirow[t]{2}{*}{$\begin{array}{l}\text { Horizonte de } \\
\text { planificación }\end{array}$} & $\begin{array}{l}\text { MJ } \\
\text { MA }\end{array}$ & & & $\begin{array}{l}\text { Incluido (+) } \\
\text { Formado } \\
\text { Incluido } \\
(+)\end{array}$ & $\begin{array}{l}\text { Incluido (+) } \\
\text { Formado } \\
\text { Incluido } \\
(+)\end{array}$ & Formado $(+)$ & \\
\hline & NM & & Alta $(+)$ & $\begin{array}{c}\text { Incluido } \\
\text { Capacitado } \\
\text { (+) }\end{array}$ & $\begin{array}{c}\text { Formado } \\
\text { Incluido } \\
\text { Capacitado (+) }\end{array}$ & Formado (+) & \\
\hline
\end{tabular}

${ }^{5}$ Las estimaciones pueden ser pedidas a los autores. 
Tabla 6 (continuación). Resumen de los resultados para las variables de competencia financiera por grupo de población y comportamiento financiero

\begin{tabular}{|c|c|c|c|c|c|c|c|}
\hline & & & & \multicolumn{4}{|c|}{ VARIABLES DE COMPETENCIA FINANCIERA } \\
\hline & & \multicolumn{2}{|c|}{ Modelo 1} & \multirow{2}{*}{$\begin{array}{c}\text { Modelo } 2 \\
\text { Compet. fin. } \\
\text { (cuentas ahorro } \\
+ \\
\text { cultura fin. } \\
\text { alta) } \\
\end{array}$} & \multirow{2}{*}{$\begin{array}{c}\text { Modelo } 3 \\
\text { Compet. fin. } \\
\text { (cuentas ahorro } \\
+ \\
\text { cultura fin. } \\
\text { media) }\end{array}$} & \multirow{2}{*}{$\begin{array}{c}\text { Modelo } 4 \\
\text { Compet. fin. } \\
\text { (tarjeta créd. } \\
+ \\
\text { cultura fin. } \\
\text { alta) } \\
\end{array}$} & \multirow{2}{*}{$\begin{array}{c}\text { Modelo } 5 \\
\text { Compet. fin. } \\
\text { (tarjeta créd. } \\
+ \\
\text { cultura fin. } \\
\text { media) } \\
\end{array}$} \\
\hline $\begin{array}{l}\text { Comportam./ } \\
\text { /Actitud }\end{array}$ & Submuestra & $\begin{array}{l}\text { Cultura } \\
\text { fin. }\end{array}$ & $\begin{array}{l}\text { Inclusión } \\
\text { fin. }\end{array}$ & & & & \\
\hline \multirow[t]{3}{*}{ Gasto } & MJ & & Alta (-) & Formado (-) & Capacitado (-) & $\begin{array}{c}\text { Formado } \\
\text { Incluido } \\
\text { Capacitado } \\
(-)\end{array}$ & $\begin{array}{c}\text { Incluido } \\
\text { Capacitado } \\
(-)\end{array}$ \\
\hline & MA & & $\begin{array}{c}\text { Media } \\
(-)\end{array}$ & & & $\begin{array}{c}\text { Incluido } \\
(-)\end{array}$ & \\
\hline & NM & & & Incluido (-) & & & \\
\hline \multirow[t]{2}{*}{$\begin{array}{l}\text { Fondos de } \\
\text { emergencia }\end{array}$} & $\begin{array}{l}\text { MJ } \\
\text { MA }\end{array}$ & & $\begin{array}{c}\text { Media (+) } \\
\text { Media } \\
\text { Alta } \\
(+)\end{array}$ & $\begin{array}{c}\text { Capacitado } \\
\qquad(+)\end{array}$ & & Incluido (+) & $\begin{array}{c}\text { Incluido } \\
\text { Capacitado } \\
(+)\end{array}$ \\
\hline & NM & Alta (+) & $\begin{array}{l}\text { Media } \\
\text { Alta } \\
(+)\end{array}$ & $\begin{array}{c}\text { Formado } \\
\text { Incluido } \\
\text { Capacitado } \\
\quad(+)\end{array}$ & $\begin{array}{c}\text { Formado } \\
\text { Incluido } \\
\text { Capacitado (+) }\end{array}$ & $\begin{array}{c}\text { Formado } \\
\text { Incluido } \\
\text { Capacitado } \\
\quad(+)\end{array}$ & $\begin{array}{c}\text { Formado } \\
\text { Incluido } \\
\text { Capacitado } \\
\quad(+)\end{array}$ \\
\hline \multirow[t]{2}{*}{$\begin{array}{l}\text { Retraso } \\
\text { en pagos }\end{array}$} & $\begin{array}{l}\text { MJ } \\
\text { MA }\end{array}$ & Alta $(-)$ & Media (-) & $\begin{array}{l}\text { Capacitado (-) } \\
\text { Capacitado (-) }\end{array}$ & Capacitado (-) & $\begin{array}{c}\text { Incluido } \\
\text { Capacitado } \\
(-)\end{array}$ & \\
\hline & NM & $\begin{array}{c}\text { Media } \\
\text { Alta } \\
(-) \\
\end{array}$ & $\begin{array}{c}\text { Media } \\
\text { Alta } \\
(-) \\
\end{array}$ & $\begin{array}{c}\text { Incluido } \\
\text { Capacitado } \\
(-)\end{array}$ & $\begin{array}{c}\text { Incluido } \\
\text { Capacitado } \\
(-)\end{array}$ & $\begin{array}{c}\text { Incluido } \\
\text { Capacitado } \\
(-)\end{array}$ & $\begin{array}{c}\text { Incluido } \\
\text { Capacitado } \\
(-)\end{array}$ \\
\hline \multirow[t]{2}{*}{$\begin{array}{l}\text { Carga } \\
\text { financiera }\end{array}$} & $\begin{array}{l}\text { MJ } \\
\text { MA }\end{array}$ & $\begin{array}{l}\text { Baja } \\
\text { Media } \\
(-)\end{array}$ & & $\begin{array}{c}\text { Incluido } \\
\text { Capacitado } \\
(-)\end{array}$ & $\begin{array}{c}\text { Formado } \\
\text { Incluido } \\
\text { Capacitado } \\
(-)\end{array}$ & & Formado $(-)$ \\
\hline & NM & $\begin{array}{c}\text { Media } \\
\text { Alta } \\
(-) \\
\end{array}$ & Media (-) & Incluido (-) & $\begin{array}{c}\text { Incluido } \\
\text { Capacitado } \\
(-)\end{array}$ & & \\
\hline \multirow[t]{2}{*}{$\begin{array}{l}\text { Satisfacción } \\
\text { financiera }\end{array}$} & $\begin{array}{l}\text { MJ } \\
\text { MA }\end{array}$ & & & & & & Formado (+) \\
\hline & NM & Alta (+) & $\begin{array}{c}\text { Media } \\
\text { Alta } \\
(+)\end{array}$ & $\begin{array}{c}\text { Incluido } \\
\text { Capacitado } \\
\qquad+(+)\end{array}$ & $\begin{array}{c}\text { Incluido } \\
\text { Capacitado } \\
(+)\end{array}$ & $\begin{array}{c}\text { Capacitado } \\
(+)\end{array}$ & \\
\hline
\end{tabular}

Notas: La Tabla 6 recoge los resultados, para las variables independientes de interés, que resultaron significativos por $<0,10$. En todos los modelos estimados se incluyen todas las variables de control definidas en la Tabla 4. Los pesos muestrales han sido utilizados. MJ/MA/NM se refieren a millennials jóvenes, millennials adultos y no millennials, respectivamente. $(+) /(-)$ indican una relación positiva o negativa, respectivamente. En la variable cultura financiera las categorías son: Alta (tres respuestas correctas), Media (dos respuestas correctas) y Baja (una respuesta correcta), siendo la categoría de referencia Ninguna ( 0 respuestas correctas). En la variable inclusión financiera las categorías son: Alta (dos productos) y Media (un producto), siendo la categoría de referencia Baja (0 productos). En el resto de las variables de competencia financiera las categorías son: Capacitado, Incluido y Formado, siendo la categoría de referencia Excluido. Fuente: elaboración propia.

Adicionalmente, se analizó la potencial existencia de multicolinealidad en los modelos propuestos, utilizando para ello el factor de inflación de la varianza (VIF, por sus siglas en inglés). Estos problemas 
fueron descartados, ya que los valores del factor de inflación de la varianza no se alejaban en exceso del valor unitario.

Las estimaciones indican que la variable cultura financiera apenas muestra relaciones significativas con los comportamientos estudiados (en un 33\% de los modelos). Por su parte, la variable inclusión financiera guarda una mayor relación con las variables dependientes (en un $48 \%$ de los modelos). Por tanto, ambas variables por separado apenas contribuyen a explicar los comportamientos y/o actitudes financieras de los encuestados, con independencia de su rango de edad. Sin embargo, la combinación de ambas a través de las variables de competencia financiera, y en particular de la que conjuga cuentas de ahorro y cultura financiera alta, que resultó significativa en un $67 \%$ de los modelos estimados, presenta un mayor grado de asociación con las actitudes financieras analizadas. Por su parte, las variables de competencia financiera referidas a la tenencia de tarjetas de crédito, un producto más extendido que las cuentas de ahorro, tienen un menor poder explicativo. La diferencia entre ambas radica en la inclusión financiera, en lugar de en la cultura financiera. Por tanto, los resultados sugieren, de nuevo, que la inclusión financiera guarda una mayor relación con los comportamientos que el nivel de conocimientos financieros del individuo. En este aspecto, nuestros resultados coinciden, en cierta medida, con los encontrados por Friedline y West (2016).

Los resultados también ofrecen conclusiones interesantes cuando la comparativa se realiza atendiendo a las variables dependientes. Así, hay algunos comportamientos, como la presupuestación, y algunas actitudes, como la satisfacción financiera, que no presentan casi relación con las variables independientes objeto de estudio. Por el contrario, estas últimas resultaron significativas en un $80 \%$ de los modelos que explicaban el retraso en pagos, un $73 \%$ de los que explicaban la posesión de fondos de emergencia y en un $67 \%$ de los que lo hacían con el horizonte de planificación. En términos generales, un mayor nivel de competencia financiera se relaciona negativamente con incurrir en retrasos en pagos en los últimos doce meses, mientras mantiene una relación positiva con el mantenimiento de fondos de emergencia para hacer frente a los gastos corrientes por lo menos durante tres meses y con tener un horizonte de planificación financiera a largo plazo.

Finalmente, la competencia financiera de los individuos también resultó significativa en aproximadamente la mitad de los modelos que explicaban el exceso de gasto y la percepción de una excesiva carga financiera. De este modo, para los millennials jóvenes se aprecia una relación negativa entre la capacitación financiera e incurrir en excesos de gasto; a mayor capacitación, menor probabilidad de tener unos ingresos inferiores a los gastos corrientes durante el último año. Esta relación apenas se confirma para las otras dos submuestras. En cambio, es en el caso de los millennials adultos y de los no millennials donde se constata una asociación negativa entre su competencia financiera y la percepción de estar excesivamente enduedados (carga financiera).

Las conclusiones que se pueden extraer por cohortes de edad son también relevantes. De los 35 modelos estimados para cada submuestra, en el $80 \%$ de los referidos a los no millennials alguna de las variables independientes de interés resultó significativa. Este porcentaje se reduce al $46 \%$ y al $37 \%$ de los modelos para el caso de los millennials adultos y jóvenes, respectivamente. Este resultado podría deberse, en parte, a un efecto derivado de los tamaños tan diferentes entre muestras ${ }^{6}$. A pesar de esta limitación, se considera igualmente que la relación que mantienen algunos comportamientos con la competencia financiera es más similar entre los millennials adultos y los no millennials (horizonte de planificación, fondos de emergencia y carga financiera), que cuando se compara a los primeros con los jóvenes de su generación (millennials jóvenes), por ejemplo, exceso de gasto. Ello puede explicarse, de alguna manera, porque los millennials adultos se encuentren en una etapa de su ciclo vital donde deben afrontar situaciones y decisiones financieras más semejantes a las de los no millennials que a las de los jóvenes millennials.

Por último, en lo que respecta a los objetivos principales de este trabajo, los resultados obtenidos coinciden parcialmente con los de Friedline y West (2016). Así, en las tres variables dependientes similares estas autoras encontraban que los millennials "financieramente capacitados" es más probable

${ }^{6}$ Nótese que en los modelos referidos a la satisfacción financiera solo ha resultado relevante para los no millennials. 
que tengan una mayor satisfacción financiera y que cuenten con fondos de emergencia, y tengan, por el contrario, una menor probabilidad de percibirse excesivamente endeudados. Estos dos últimos resultados se replican en nuestro estudio;. Sin embargo, lo hacen solo para la muestra de millennials adultos, no encontrándose evidencias empíricas suficientes de estas relaciones para los millennials jóvenes.

Con respecto a las variables de control, se ha hallado que, excluyendo el subgrupo millennials jóvenes, las mujeres tienen una mayor probabilidad de plantearse objetivos financieros a largo plazo (horizonte de planificación) y, dentro de los no millennials, muestran una mayor satisfacción financiera.

Los modelos también constatan que la mayor edad de los millennials adultos se relaciona negativamente con el establecimiento de objetivos financieros a largo plazo, y positivamente con la percepción de estar excesivamente endeudados (carga financiera), coincidiendo en ambos aspectos con los no millennials. Curiosamente, entre los millennials jóvenes, a medida que aumenta su edad disminuye su satisfacción financiera.

Con independencia de la cohorte generacional analizada, estar empleado se asocia positivamente con la disponibilidad de fondos de emergencia y con la satisfacción financiera; también, en el caso de los millennials adultos, con un horizonte de planificación financiera a más largo plazo. En el caso de los millennials jóvenes, reduce su probabilidad de mostrar un déficit doméstico (gasto).

A grandes rasgos, los mayores ingresos de la unidad familiar ejercen los efectos esperables sobre las variables de gasto, retrasos en pagos, carga financiera, fondos de emergencia y satisfacción financiera, con independencia del grupo de edad analizado.

Asimismo, el mayor nivel educativo se relaciona con una conducta financiera más solvente, fundamentalmente entre los millennials, con una mayor presencia de fondos de emergencia específicamente entre los más jóvenes que, además, tendrán un horizonte de planificación financiera más largo y una menor probabilidad de mostrar retrasos en pagos. Por otra parte, y con independencia del grupo de edad, una mayor educación reduce la probabilidad de percibirse excesivamente endeudado.

La tenencia de hijos menores a cargo parece afectar en mayor medida a los millennials adultos, que mostrarían un mayor déficit doméstico y mayores cargas financieras. Por otro lado, la convivencia con el cónyuge o pareja apenas se relaciona con ningún comportamiento financiero, con independencia de la submuestra considerada. En el caso de los millennials, se relaciona positivamente con una mayor presupuestación (millennials adultos) y con establecer objetivos financieros a largo plazo (millennials jóvenes).

Finalmente, la aversión al riesgo parece asociarse negativamente con el establecimiento de objetivos financieros a largo plazo en todos los grupos de edad, relacionándose en mayor medida con los comportamientos de los no millennials (positivamente con el gasto y negativamente con la posesión de fondos de emergencia y con la satisfacción financiera).

\section{Conclusiones}

En el contexto económico-financiero actual, la capacitación financiera se ha convertido en un aspecto de gran relevancia para el desarrollo económico y social. Esta circunstancia es más relevante, si cabe, entre la generación millennial, recientemente incorporada al mercado laboral y con unas características muy particulares con respecto a las generaciones anteriores. Por ello, es de gran relevancia explorar cómo están de preparados y qué capacidad tienen los millennials para enfrentarse a un mercado financiero donde los productos y las relaciones son cada vez más complejas y en el que las decisiones han de tomarse en un contexto de volatilidad y complejidad financiera nunca antes experimentado. Por este motivo, los principales objetivos de este trabajo han sido conocer la competencia financiera de los millennials españoles (objetivo 1), y explorar cómo esa capacitación se relaciona con sus actitudes y comportamientos financieros (objetivo 2) en comparación con las generaciones precedentes (objetivo 3). A fin de alcanzar estos objetivos, la investigación ha utilizado una muestra de 6.852 personas no jubiladas menores de 65 años en la que el 34\% son millennials. 
Sobre el primero de los objetivos, los resultados muestran que los millennials, y en particular los más jóvenes, tienen un menor acceso a los productos analizados y un menor nivel de cultura financiera respecto de los no millennials. Como resultado, también presentan un menor nivel de capacitación financiera, especialmente los millennials jóvenes. Ese nivel de competencia financiera está más condicionado por la cultura financiera que por los productos financieros al alcance de los individuos.

A pesar de que los conocimientos financieros condicionan en mayor medida el nivel de capacitación financiera de las personas, cuando esta se relaciona con las actitudes y comportamientos financieros (objetivo 2), tales comportamientos guardan una relación mayor con la inclusión que con la cultura financiera. En este sentido, las evidencias obtenidas acerca de los potenciales drivers de actitudes y decisiones financieras inclinan la balanza hacia los argumentos basados en el learning by doing sugeridos por la literatura (Moreno-Herrero et al., 2018b).

Nuestros resultados no han mostrado una relación significativa entre la competencia financiera y comportamientos y actitudes como la presupuestación y la satisfacción financiera. En cambio, aquellas aparecen muy relacionadas con el retrasos en pagos (negativamente) y con el mantenimiento de fondos de emergencia y horizontes de planificación largos (positivamente). En el resto de comportamientos analizados (gasto y carga financiera), la relación con la capacitación financiera va a depender más del subgrupo de edad considerado.

Las conclusiones que se pueden extraer por grupos generacionales también resultan interesantes (objetivo 3). En general, la competencia financiera está más asociada con las actitudes y comportamientos financieros de los no millennials. Este resultado podría obedecer, en cierto modo, a los tamaños tan diferentes entre muestras. No obstante, también se aprecia que la relación que mantienen algunos comportamientos con la capacitación financiera es más similar entre los millennials adultos y los no millennials (véase horizonte de planificación, fondos de emergencia y carga financiera), que cuando se compara a los primeros con sus congéneres. Ello es atribuible a que los millennials adultos se encuentren en un período de su ciclo vital en el que han de tomar decisiones financieras más semejantes a las de los no millennials que a las de los jóvenes millennials. En este sentido, se percibe la necesidad de seguir profundizando en el estudio de esta generación, en sus características y en sus comportamientos.

La principal aportación de este trabajo, por tanto, es contribuir con nuevas evidencias empíricas al campo de estudio de los comportamientos y competencias financieras de los millennials, en un contexto sociocultural -el español- no analizado hasta este momento. Además, dados los distintos ciclos vitales en los que pueden encontrarse los individuos de la generación millennial, el trabajo permite diferenciar comportamientos y competencias entre jóvenes y adultos millennial. De esta forma, supone una extensión y/o contraste de los resultados alcanzados por Friedline y West (2016) en su investigación realizada en el contexto estadounidense, y conforma una aproximación robusta al análisis de los comportamientos financieros de la generación más numerosa y que constituye el núcleo de los mercados actuales. Por tanto, futuros trabajos deberán seguir profundizando en dicho análisis. Por otro lado, en el ámbito de la gestión los resultados muestran que las Administraciones y gobiernos deben seguir invirtiendo en la capacitación financiera de su población, tratando de garantizar el acceso a los productos financieros óptimos con el afán de erradicar y prevenir "malos hábitos financieros".

Por último, las líneas futuras de trabajo parten de las principales limitaciones encontradas. Estas giran alrededor de dos aspectos: la muestra y la definición de las variables. En relación con la muestra, destacaríamos el relativamente bajo porcentaje de millennials que incorpora (alrededor del 34\%). Esta proporción es comprensible dentro del objetivo de la ECF, y teniendo en cuenta que su proceso de muestreo se ajusta a la distribución de la población española, pero resulta escasa cuando se pretende poner el foco de estudio en los millennials. En futuros estudios se debería contar con una muestra mayor o, por los menos, con submuestras más equilibradas, aunque, como se ha referido al comienzo de este trabajo, las bases de datos con información sobre millennials han sido hasta el momento limitadas. Además, sería interesante disponer de datos para más años de cara a establecer tendencias temporales en los resultados. En este sentido, los datos fueron obtenidos entre finales del año 2016 y el 
2017, pero sería deseable contar con datos actualizados para ver la influencia de la segunda gran crisis que afecta a los millennials en lo que va de siglo (la del COVID-19).

En relación con la definición de las variables, como se ha visto, hemos trabajado fundamentalmente con variables categóricas que se han construido a partir de los datos disponibles y siguiendo el patrón de Friedline y West (2016) adaptado a la realidad española. Sin embargo, en futuros trabajos sería deseable moverse hacia una variable continua, tal y como sucede con aquellas puntuaciones que miden la competencia financiera de los estudiantes de 15 años en los informes PISA.

Otra cuestión que es necesario analizar en profundidad en futuras ampliaciones de esta investigación es la posible endogeneidad de la variable cultura financiera con otras variables contenidas en el estudio, y en particular con la propia inclusión financiera, tal y como refieren van Rooij, Lusardi y Alessie (2012) en su estudio de los determinantes de la planificación para la jubilación.

\section{Bibliografía}

Anderloni, L., Bayot, B., Bledowski, P., Iwanicz-Drozdowska, M., y Kempson, E. (2008). Financial services provision and prevention of financial exclusion. Brussels, Belgium: European Commission. Recuperado de: https://www.bristol.ac.uk/media-library/sites/geography/migrated/documents/pfrc0807.pdf

Banco de España. (2019). The Survey of Financial Competences (ECF) 2016 User Guide. Madrid: Banco de España. Recuperado de: https://www.bde.es/f/webbde/SES/estadis/otras estadis/2016/UserGuide ECF.pdf

Bover, O., Hospido, L., y Villanueva, E. (2019). The Survey of Financial Competences (ECF): Description and methods of the 2016 wave. Banco de España Occasional Paper No. 1909. Madrid: Banco de España. DOI: https://doi.org/10.2139/ssrn.3396964

Campos, J. (2019). La educación financiera como base de la cultura del ahorro y la previsión social. Barcelona: Universitat de Barcelona.

Recuperado de: http://diposit.ub.edu/dspace/bitstream/2445/144301/1/TFM-DEAF-240 Campos.pdf

Cole, S., Paulson, A., y Shastry, G. K. (2016). High school curriculum and financial outcomes: The impact of mandated personal finance and mathematics courses. Journal of Human Resources, 51(3), 656-698.

DOI: https://doi.org/10.3368/ihr.51.3.0113-5410r1

Cordero, J. M., y Pedraja, F. (2019). The effect of financial education training on the financial literacy of Spanish students in PISA. Applied Economics, 51(16), 1679-1693.

DOI: https://doi.org/10.1080/00036846.2018.1528336

Cornejo-Saavedra, E., Umaña-Hermosilla, B., Guíñez Cabrera, N., Muñoz-Silva, D., y Mardones-Lagos, C. (2017). Endeudamiento y educación financiera del adulto joven en Chile. RAN: Revista Academia \& Negocios, 3(2), 33-44. Recuperado de: https://dialnet.unirioja.es/servlet/articulo?codigo=6229834

Cramer, R. (2014). Millennials rising: Coming of age in the wake of the great recession. New America, 11-16. Recuperado de: https://d1y8sb8igg2f8e.cloudfront.net/documents/Millennials Rising Coming of Age in the Wake of the G reat Recession hPH6qs7.pdf

Cutler, N. E. (2015). Millennials and finance: The "Amazon generation". Journal of Financial Service Professionals, 69(6), 33-39.

de Bassa, C., Lusardi, A., y Yakoboski, P. J. (2014). College-Educated millennials: An overview of their personal finances. New York, NY: TIAA-CREF Institute. Recuperado de: https://millennialmoney.com/wp-content/uploads/2015/09/millennials personal finances feb2014.pdf

Fernández-López, S., Vivel-Búa, M., Rey-Ares, L., y Sixto-Puente, E. (2020). Ahorro y jubilación entre los "millennials" españoles: un enfoque exploratorio. European Journal of Applied Business and Management, 6(1), 24-47. Recuperado de: http://nidisag.isag.pt/index.php/IJAM/article/view/481

Foster, F. D., Ng, J., y Wee, M. (2015). Presentation format and financial literacy: Accessibility and assessability of retirement savings statements. Journal of Consumer Affairs, 49(3), 519-549. DOI: https://doi.org/10.1111/joca.12087

Friedline, T., y West, S. (2016). Financial education is not enough: Millennials may need financial capability to demonstrate healthier financial behaviors. Journal of Family and Economic Issues, 37(4), 649-671. DOI: https://doi.org/10.1007/s10834-015-9475-y

Global Financial Literacy Excelence Center. (2020). S\&P Global FinLit Survey. Washington, DC: Global Financial Literacy Excelence Center. Recuperado de: https://gflec.org/initiatives/sp-global-finlit-survey/ 
Hastings, J. S., Madrian, B. C., y Skimmyhorn, B. (2013). Financial literacy, financial education, and economic outcomes. Annual Review of Economics, 5, 347-373.

DOI: https://doi.org/10.1146/annurev-economics-082312-125807

Kim, K. T., Anderson, S. G., y Seay, M. C. (2019). Financial knowledge and short-term and long-term financial behaviors of millennials in the United States. Journal of Family and Economic Issues, 40(2), 194-208. DOI: https://doi.org/10.1007/s10834-018-9595-2

Klapper, L., Lusardi, A., y van Oudheusden, P. (2015). Financial literacy around the world. Insights from the Standard \& Poor's Ratings Services Global Financial Literacy Survey. Washington, DC: Standard \& Poor's. Recuperado de:

https://responsiblefinanceforum.org/wp-content/uploads/2015/12/2015-Finlit paper_17_F3 SINGLES.pdf

Lövgren, A., y Magnusson, M. (2016). Exploring how to engage Swedish millennial with pension planning. (Master of Science Thesis INDEK 2016:49KTH Industrial Engineering and Management). Stockholm, Sweden: KTH Industrial Engineering and Management.

Recuperado de: http://www.diva-portal.org/smash/get/diva2:947275/FULLTEXT01.pdf

Lusardi, A., y Mitchell, O. S. (2007). Financial literacy and retirement planning in the United States. Journal of Pension Economics and Finance, 10(04), 509-525. DOI: https://doi.org/10.1017/S147474721100045X

Lusardi, A., y Mitchell, O. S. (2011). Financial literacy around the world: An overview. NBER Working Paper 17107. Cambridge, MA: National Bureau of Economic Research (NBER).

Recuperado de: https://www.nber.org/papers/w17107

Lusardi, A., y Mitchell, O. S. (2014). The economic importance of financial literacy: Theory and evidence. Journal of Economic Literature, 52(1), 5-44. DOI: https://doi.org/10.1257/jel.52.1.5

Mancebón, M. J., Ximénez-de-Embún, D. P., Mediavilla, M., y Gómez-Sancho, J. M. (2019). Factors that influence the financial literacy of young Spanish consumers. International Journal of Consumer Studies, 43(2), $227-235$. DOI: https://doi.org/10.1111/ijcs.12502

McLendon, T. (2016). The millennial investor: Mutual funds versus exchange traded funds. (An Honors Thesis submitted in partial fulfillment of the requirements for the degree Bachelor of Science in Business Administration in Finance). Fayetteville, AR: Sam M. Walton College of Business. University of Arkansas. Recuperado de:https://scholarworks.uark.edu/cgi/viewcontent.cgi?referer=https://scholar.google.es/\&httpsredir=1\&art icle $=1024 \&$ context=finnuht

Ministerio de Educación, Cultura y Deporte. (2014). PISA 2012: competencia financiera. Informe español. Madrid: Secretaría General de Documentación y Publicaciones. Recuperado de: https://sede.educacion.gob.es/publiventa/pisa-2012-competencia-financiera-informe-espanol/ensenanzafinanzas $/ 20001$

Molina, J. A., Marcenaro, O., y Martín, A. (2015). Educación financiera y sistemas educativos en la OCDE: un análisis comparativo con datos PISA 2012. Revista de Educación, 369, 85-108.

Recuperado de: https://sede.educacion.gob.es/publiventa/d/20398/19/0

Moreno-Herrero, D., Salas-Velasco, M., y Sánchez-Campillo, J. (2018a). The knowledge and skills that are essential to make financial decisions: First results from PISA 2012. FinanzArchiv: Public Finance Analysis, 74(3), 293-339. DOI: https://doi.org/10.1628/fa-2018-0009

Moreno-Herrero, D., Salas-Velasco, M., y Sánchez-Campillo, J. (2018b). Factors that influence the level of financial literacy among young people: The role of parental engagement and students' experiences with money matters. Children and Youth Services Review, 95, 334-351. DOI: https://doi.org/10.1016/j.childyouth.2018.10.042

Mottola, G. R. (2014). The financial capability of young adults - A generational view. Washington, DC: FINRA Financial. Recuperado de:

https://www.finra.org/sites/default/files/14 0100\%201_IEF Research\%20Report CEA 3\%206\%2014\%20 \%28FINAL\%29 0 0.pdf

Organisation for Economic Co-operation and Development. (2013). PISA 2012 assessment and analytical framework: Mathematics, reading, science, problem solving and financial literacy. Paris, France: OECD. Recuperado de:

https://www.oecd.org/pisa/pisaproducts/PISA\%202012\%20framework\%20e-book final.pdf

Organisation for Economic Co-operation and Development. (2016). PISA 2015 assessment and analytical framework: Science, reading, mathematic and financial literacy. Paris, France: OECD. Recuperado de: https://www.oecd.org/publications/pisa-2015-assessment-and-analytical-framework-9789264281820en.htm

Pumares-Iglesias, T., Fernández- López, S., Vivel-Búa, M., y Rey-Ares, L. (2015). A participación no mercado de valores: por que invisten os individuos? Revista Galega de Economía, 24(1), 17-30. Recuperado de: https://revistas.usc.gal/index.php/rge/article/view/2681 
Rodríguez-Castellanos, A. (2019). Complejidad, incertidumbre y crisis financiera. En A. M. Gil-Lafuente (Coord.), Complejidad financiera: mutabilidad e incertidumbre en instituciones, mercados y productos (pp. 111-138). Barcelona: Real Academia de Ciencias Económicas y Financieras.

Sherraden, M. S. (2013). Building blocks of financial capability. En J. Birkenmaier, M. S. Sherraden y J. Curley (Eds.), Financial education and capability: Research, education, policy, and practice (pp. 3-43). New York, NY: Oxford University Press.

Shim, S., Barber, B. L., Card, N. A., Xiao, J. J., y Serido, J. (2010). Financial socialization of first-year college students: The roles of parents, work, and education. Journal of Youth and Adolescence, 39(12), 1457-1470. DOI: https://doi.org/10.1007/s10964-009-9432-x

Van Rooij, M., Lusardi, A., y Alessie, R. (2012). Financial literacy, retirement planning and household welath. The Economic Journal, 122(560), 449-478. DOI: https://doi.org/10.1111/j.1468-0297.2012.02501.x

Yao, R., y Cheng, G. (2017). Millennials' retirement saving behavior: Account ownership and balance. Family and Consumer Sciences Research Journal, 46(2), 110-128. DOI: https://doi.org/10.1111/fcsr.12241 